\title{
Editorial
}

https://doi.org/10.11646/megataxa.1.2.1

\section{Taxonomy as the key to life}

\author{
MARK J. COSTELLO \\ Faculty of Bioscience and Aquaculture, Nord Universitet, Postboks 1490, 8049 Bodø, Norway; and School of Environment, University of \\ Auckland, Auckland 1142, New Zealand. \\ "mark.j.costello@nord.no ○ https://orcid.org/0000-0003-2362-0328
}

\begin{abstract}
Taxonomy is a key to life not only in providing guides to distinguishing species but in opening the door to knowledge about biodiversity. Names of species, as the only standardised measure of biodiversity, are essential for communication of information about nature. However, new knowledge means that what we understand each species to be may change over time. Online species databases are improving accessibility to this knowledge and expertise and provide an easy way to keep up to date with species nomenclature and classification. I propose three practical priorities for taxonomy: (1) complete a world list of all known species; (2) establish an online cooperative community infrastructure that updates species nomenclature and links it to associated literature, information and expertise; (3) create an internet portal as a key to life on Earth. The first is near completion in the Catalogue of Life. The second has an exemplar in the World Register of Marine Species. The third goal has not begun but some of its ingredients exist. This key to life should make it easy for anybody with internet access to accurately name, and discover unnamed, species, and learn about their natural history. Moreover, a "key to life" infrastructure suitably supported by the community and science organisations, could be a focal point for a world taxonomic society and a taxonomy based mega-science initiative to understand life on Earth.
\end{abstract}

Key words: databases, checklists, species, taxa, biodiversity, Earth, oceans

\section{Introduction}

Why life exists interests everyone. If we want to know about all life on Earth, then we must support taxonomy because it is the starting point of such research. The first step is giving a species a name, leading to more in-depth knowledge of its evolution, ecology, and biology. The species name is the first of three 'keys' to opening the doors to the library of nature.

\section{Species names}

To give names is to recognize something's significance, be it a person, place, phenomenon, substance, or species. To give names to species is to recognize and respect nature. Just as with names for people and places we need names for species so we can communicate information about them. As such, taxonomy may be the oldest science, and is indeed referenced in the Bible and Sikh scriptures about 2,500 and 1,000 years ago respectively. The Bible says that God asked man to name all species (Boero 2010) and the Sikh scriptures reported there were 8.4 million 'species' on Earth.

The practical purpose of naming species may sometimes get overlooked in debates about theoretical concepts (Christenhusz 2020). This purpose means that what are defined as species must be populations with enduring phenotypic features that distinguish them from other populations. These features likely relate to differences in evolution so the uniqueness of populations may be reflected in their morphology, physiology, behaviour, habitat preferences, ecology, genes, and/or geographic distribution. Where these characteristics form a continuum across individual specimens then this is within-species variation. Where characters present clear differences between groups of specimens this is grounds for a hypothesis that they are different species. However, this hypothesis cannot be certain until differences between sexes, ages, life-stages, and growth forms have been studied.

The Linnaean system is the world standard for species names, but we also have names for subspecies and for the numerous varieties of farmed fruit, vegetables and animals we need to share information on. Not only can we not accurately communicate this information in science and society without standard naming systems, but we cannot manage and protect species without a quality assured system for naming species, including, for example, synonymies and misspellings.

It can be curious and frustrating when species names change, but it should not be a complete surprise. The names of people, streets and other places also change and have 
alternative forms that can cause problems for databases. As with species, the concept of what a country or nation is may change over time as its boundaries change. Over time, many taxa regarded as one species may become recognized as more than one, and vice versa, some names may become synonymized when it is realized they apply to the same species. This changing knowledge inevitably means that names may refer to something different over time, a feature of nomenclature that is often not clear in online databases and the literature. For example, a publication may report the geographic distribution or aspects of the ecology or biology of a 'species' but that species name may now refer to several species. Only by checking a more recent publication will the user be aware that the application of the name has changed over time. Hence a benefit of online species lists is users can check if what they are studying fully matches the species they may have assumed it was, or whether for example, it is a close relative. It is thus best practice in the use of species names to check them against current nomenclature (Costello \& Wieczorek 2014).

Rather than try to 'stabilize' names what is needed is a quality assured way to link together names that mean the same thing, or close to the same thing (Thomsen et al. 2018). Such systems have been developed and could be extended to all species (Costello et al. 2018, Kroh et al. 2019). For example, the World Register of Marine Species (WoRMS) is a centralized open-access online database of all marine and many other species whose nomenclature is continually updated by a community of about 300 taxonomic editors (Costello et al. 2013a). It has an automated tool to provide users a classified list of how their species names match what is in WoRMS, thereby improving the accuracy of species names being used in the literature and other databases.

So far, I have focused on the importance of species names, concepts, and managing nomenclature. However, taxonomy is not only the science of naming, but also of describing biodiversity, i.e., natural history (Dayton \& Sala 2001; Anderson 2017; Christenhusz 2020). The process of naming involves at least describing what a species looks like, where it lives, and its relationships to related species so people can distinguish them. This extends beyond the 'what', to 'where', 'when' and the 'why'- the species' natural history, ecology and how it evolved. It is not the name that is important but what the name stands for, as each name is the label for a concept and hypothesis that will be developed with further study. Taxonomy is better advanced in its first phase of naming species than some admit and has long been delving deeper into understanding species evolution, biology and ecology. This includes providing guides to species identification and natural history to make primary knowledge available to students and society.

\section{Taxonomic practice}

Seven years ago, several actions were proposed to improve taxonomic efficiency (Costello et al. 2013b). Those regarding publication are now normal practice: more rapid publication; immediate online publication upon acceptance of papers; more taxonomic revisions of species groups to recognise synonyms and clarify their relationships; and registration of new species. Most other proposed actions are underway: expert-validated openaccess inventories of all described species on Earth, linked to literature, distribution and other information by cooperatives of taxonomists; online interoperability between publications, databases, and scholarly web sites so that authoritative information is more easily found; and greater access to taxonomic literature that helps identify, and recognise undescribed, species, e.g., the Biodiversity Heritage Library (BHL Consortium 2020); coordinated field sampling for species in geographic areas and habitats that are likely to add substantially to the world's collections; international cooperation to facilitate exploration, discovery and description of new species; use of digital imaging and molecular technologies to accelerate the description of species; and financial support from government and non-government sources to support open-access to taxonomic publications and scholarly databases, and fund travel to visit museum collections.

Other recommendations include engagement with citizen scientists for observing and collecting specimens, and notable successes are for example, 'iNaturalist' which records specimens and observations (Unger et al. 2020), 'eBird' which maps birds globally over time (Sullivan et al. 2014), and the Reef Life Survey which counts coral and rocky reef fish at thousands of sites around the world (Edgar \& Stuart-Smith 2014). Already, significant numbers of new species insects and other taxa are described by people not employed for the task, e.g., half of European animals (Fontaine et al. 2012). However, beyond these exemplars, it is not clear if there is enough global coordination amongst the scientific community, both professional and amateur, to share taxonomic knowledge and fill gaps in expertise; and establish new appointments of taxonomists in countries with rich diversity.

Since the above actions were proposed image analysis software has improved greatly and it is now possible in theory, to train image recognition software to help classify and names many species. Several Smartphone 'Apps' for identifying (at least) fish, plants and birds are available and will improve in accuracy and comprehensiveness over time. These tools could revolutionise species identification and make it accessible to customs officials, students, citizens, veterinarians, medical professionals, and scientists alike. Camera traps are now widely used 
in terrestrial environments and being trialled underwater. The time taken to analyse still and video images will be reduced by automated scanning software (e.g., Wei et al. 2020). Historic series of photographs could be rapidly analysed to document trends in species abundance over time. More people may be need to be trained in taxonomy to provide quality assurance for validating image analysis systems.

\section{Three priorities for taxonomy}

The above actions are part of the methodology of doing taxonomy, in other words, means to achieve greater goals. Here I suggest three practical steps to know biodiversity:

1. Complete an annotated checklist of all named species.

2. Form an integrated, online, taxonomic community coordinated around automatically synchronized (and/or centralized), permanently hosted, global databases that maximise public access to quality assured information.

3. Publish an open-access, image-rich, key to life to enable anybody with an internet connection to identify animals and plants in the field, laboratory and at home.

Of these three priorities the first is about $85 \%$ complete. The Catalogue of Life (CoL) contains 1.3 million (Roskov et al. 2019) of the estimated 1.5 million named species (Costello et al. 2013b), and aims to list all named species (Bisby 2000). In addition, 51,000 species of algae are in AlgaeBase (Guiry and Guiry 2020), and they represent $85 \%$ of the species described under the International Code of Nomenclature for algae, fungi and plants (Guiry, 2012; M.D. Guiry pers. comm.). The lists of species in the CoL for vascular plants, Archaea, Bacteria, Fungi and Viruses, are reasonably comprehensive, as are $90 \%$ (29 of 32) of the animal phyla. The main gaps appear to be amongst 40,000 missing species of mites, around 20,000 missing species each of snails, hemipteran bugs, and nematode worms, and under 10,000 species each of flatworms, sawflies, harvestmen, and the wingless insects (Roskov et al. 2019). The fact that the numbers do not add up reflects the uncertainties in how many species may have been named in various taxa, and it is possible larger gaps exist.

We may expect numbers of accepted names to decrease in most groups with good taxonomic revisions. For example, the number of named species of flowering plants may not vary because there may be as many synonyms as new species found (Bebber et al. 2014). Similarly, the number of polychaete species in WoRMS declined by 1,200 species from 2012 to 2016, despite over one hundred new species being named every year, due to reconciliation of taxonomic nomenclature (Pamungkas et al. 2019). Thus, cleaning up present nomenclature can significantly reduce the number of presently counted species and needs to be considered in estimating what the total may be.

WoRMS demonstrates how the second goal can be achieved. Such a centralized expert-validated database could be expanded to all species on Earth, and continually expanded with ancillary information (e.g., species attributes such as if they are extant, extinct, fossil, environment, habitat, and body size) (Costello et al. 2013a, 2018; Kroh et al. 2019). Indeed, such a system is now being developed as a collaboration between the Global Biodiversity Information Facility (GBIF) and Species 2000 called the Catalogue of Life 'plus' (CoL+) (Hobern et al. 2019).

While several resources provide the content that could contribute to the third goal, namely an online Key to Life, as yet none provide an interface to help people identify any animals, plants and microbes they have come across, although its absence has been noted (Costello et al. 2012, 2015a), and it was included in the original funding application for the Encyclopedia of Life. At present, entry to the major online resources require people to already know which species they are interested in. Although (at least for European marine taxa) the numbers of species identification guides in print have been increasing since the 1970s, these have not been paralleled by online resources (Costello et al. 2006). An advantage of digital keys is users can enter at any level and select what features they have observed and recognise online. These can include body plan, habitat, geographic location, images, videos, sounds or text in multiple languages and scripts, rather than needing to follow linear hierarchies of taxonomic characters. Such keys are especially important for invertebrate groups in species rich countries where collating collections of the scientific books and papers needed to become familiar with a taxonomic group is so expensive in time and cost that most people are excluded from being able to become familiar with the taxon.

To produce a key to life, funding is needed to support training, field and laboratory work, critical reviews of nomenclature, data analysis and publication (Hutchings 2020; Borkent 2020; Britz et al. 2020). It needs to engage professionals, students and citizens and go beyond species identification and description to explore their natural history, ecology, biogeography, phylogenetics, physiology, and behaviour to more fully understand how life originates and is maintained. Thus, in addition to providing a key to identify species, I propose that such a key-to-life portal could be a focus for an international, cooperative, community-governed initiative. The infrastructure would show where the gaps are and endorse proposals to funding agencies to fill them. 


\section{Discussion}

Obstacles to advancing taxonomy are tenuous speculations that there are millions of species remaining to be discovered and/or threatened with extinction which make the goal appear hopeless (Costello et al. 2013b, c; Costello 2019). Such statements fail to adequately recognise the efforts of thousands of people who have been successfully describing species and their natural history for hundreds of years, and ignore the fact that there are more people alive today who have described a species than any time in the past, probably around 50,000 (Costello et al. 2013b) (Boxes 1, 2). This number alone suggests taxonomy is a mega-science activity. We know this because these taxonomists names are documented in the literature, and databases such as the CoL and WoRMS.

Pleading to be given more funding because taxonomy is failing or loosing expertise will not be successful because it comes across as wanting more funds for an unsuccessful endeavour. Moreover, the evidence shows that expertise is not declining at a global scale and that most species have already been named. Indeed, taxonomy is flourishing with more people involved than ever before, and more taxonomic work being published than ever before. It is exciting to think that it will be getting more difficult to discover species new to science for an increasing number of taxa in the coming decades. Rather, a call for governments and foundations to fund the completion of a checklist of all species, host permanent user-driven collaborative infrastructures for taxonomic knowledge, and build a key to life are practical goals with wide benefits to society in terms of discovering and understanding life on Earth. This increased access to taxonomic knowledge will provide more rapid, quality assured and cost-efficient identification of potential pests and pathogens, including their geographic and host distributions and means of transmission. This is as valuable as discovering chemicals to chemistry and particles to physics. Because it includes natural history, ecology, physiology, biochemistry and molecular biology, the number of variables is infinite, and we cannot imagine what secrets remain to be revealed.

Taxonomy already has commissions of species nomenclature setting rules for how names of viruses, bacteria, fungi, algae, plants, cultivated plants, and animals are recognised (David et al. 2012), several taxon specific societies', and a marine taxonomic network centred around WoRMS. The establishment of a global taxonomic society, as proposed by Zhang (2020) seems overdue. This could be the public and scientific face of the mega-science that taxonomy is. It could broker relationships between taxonomic communities, specialists and users, and champion priorities for future research.

\section{Acknowledgements}

I thank Zhi-Qiang Zhang for inviting this article, and his initiative in adding Megataxa to the world leading group of taxonomy journals he has established. I thank Don Hobern, Tony Rees, Mike Guiry, Oliver Coleman and an anonymous referee for helpful comments that improved the paper.

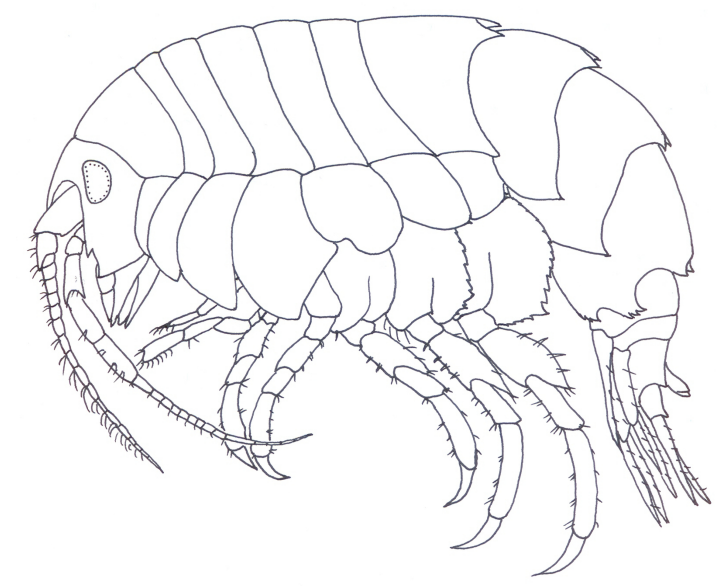

FIGURE 1. Iphimedia perplexa Myers \& Costello 1987 is a rare amphipod crustacean first described from Lough Hyne, a marine reserve in Ireland. All that is known about the species is its morphological description and some geographic distribution records.

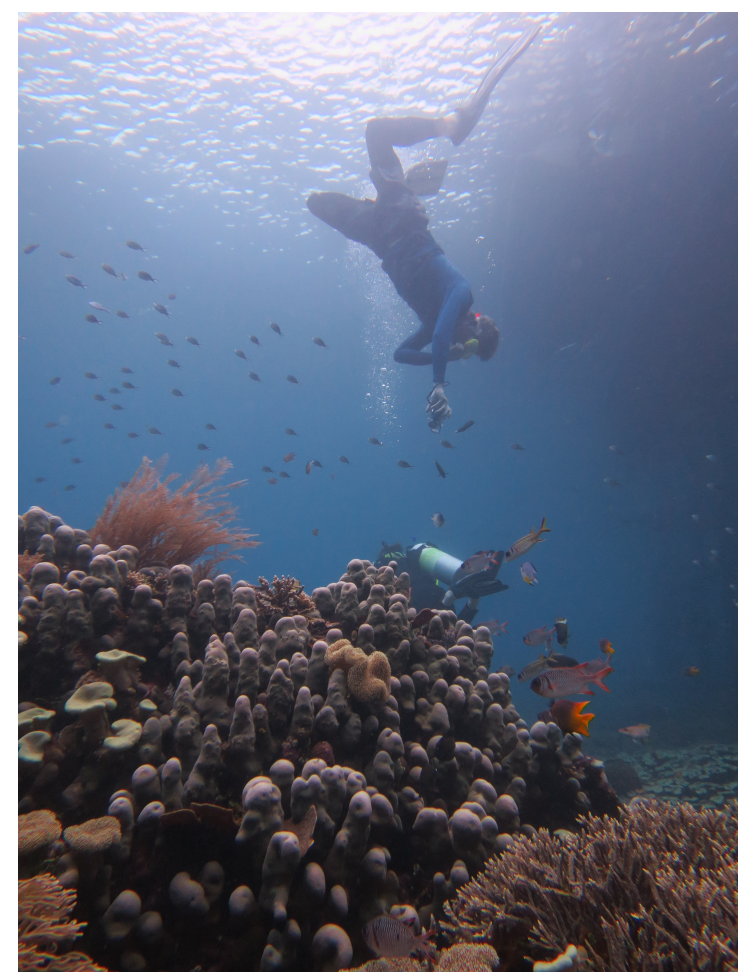

FIGURE 2. The author as a naturalist exploring marine biodiversity in Raja Ampat, Indonesia, the richest place for species in the oceans. 


\section{Box 1. Who is a taxonomist?}

Of course, not all the people who have described a species may consider themselves a taxonomist. Indeed, about $40 \%$ of authors of animal, plant and marine species have only ever described one species (Costello et al. 2012; Appeltans et al. 2012; Bebber et al. 2014). However, many people who have never described a species new to science have been considered taxonomists in reviews of taxonomy in Australia, Britain, Canada, Europe and New Zealand because they study other aspects of taxonomy such as phylogeny or being national specialists in species identification (Costello et al. 2006; Lovejoy et al. 2009; Boxshall and Self 2011; Taxonomy Decadal Plan Working Group 2018). Thus, arguably calling those who described species as a taxonomist is an underestimate. In any case, because the proportion of these part-time or once-off taxonomists has not changed in over a century, then the fact that there are so many more authors of new species, even if only first authors are counted, represents an increased taxonomic workforce (Alroy 2002; Joppa et al. 2011; Appeltans et al. 2012; Costello et al. 2012, 2013d, 2014a, 2014b; Bebber et al. 2014; Arfianti et al. 2018; Pamungkas et al. 2019; Pagès-Escolà et al. 2020).

In addition to the increasing numbers of publications of new species (Lohrmann et al. 2012; Costello et al. 2013b), there were seven times more authors of marine species in the first decade of this century than any decade before (Costello et al. 2015a). Even if only first authors of new species descriptions are counted there are several times more authors now than prior to the 1960s (Arfianti et al. 2018, Pamungkas et al. 2019, Pagès-Escolà et al. 2020). There has been a trend for more multiple authorships since the 1980s reflecting more inclusive authorship practices and more comprehensive species descriptions (Joppa et al. 2011, Costello et al. 2012). However, on close examination it is apparent that co-authors may be first authors on other new species descriptions. So, without a more detailed analysis one cannot dismiss co-authors are not being taxonomists.

Examination of the literature shows where the authors of new species descriptions work, and the increasing numbers of taxonomists in Asia, especially China, but also in South America, and no evidence of declines in other countries (Costello et al. 2013b, c, d; Deng et al. 2016, 2019; Liu et al. 2019). This is no surprise to the public and wider scientific community because the world's scientific community has been growing for decades as economies develop. However, perhaps traditional disciplines like taxonomy have not grown to the same degree as subjects like biomedicine.

Naturally the best-known taxonomists, who have been publishing for decades, will be close to or are already officially retired. This is the nature of any subject where reputation builds over time. Reviews of the age of known taxonomists in the UK, Canada and Europe indicate the average age ranges from late 30's to early 50's (Costello et al. 2006; Lovejoy et al. 2010; Boxshall \& Self 2011; Costello et al. 2013b). These reviews are biased towards more senior experts because of the difficulty in contacting early career taxonomists. Thus, while there are clearly too few taxonomists to describe the remaining species, many occurring in threatened habitats, it is not by any measure a dying profession. 


\section{Box 2. Progress in discovering species.}

The factors most influencing when new species will be described are how widespread their distribution is, and whether they occur in Europe (Costello et al. 2015b). The numbers of new species being described for some taxa appear to be nearing an asymptote: including for example marine animal taxa of Britain and Ireland (Costello et al. 1996); and European marine mammals, birds, krill and echinoderms (Costello and Wilson 2011). Some 68\% of European marine species (Costello and Wilson 2011), about half of western Indian Ocean and South African marine species (Griffiths 2005), and 75\% of collected species from New Zealand's seas (Gordon et al. 2010) are estimated to be described. It is estimated that $99 \%$ of birds, $94 \%$ of mammals, $85 \%$ of amphibians and $80 \%$ plants of Brazil have been described (Pimm et al. 2010).

Global scale assessments of taxa estimate that well-over half have been named: $>80 \%$ butterflies, birds and mammals, flowering plants, water bugs (Robbins and Opler 1997; Polhemus and Polhemus 2007, Bebber et al. 2007, 2014; Woodley et al. 2009; Joppa et al. 2011; Giam et al. 2012; Tedesco et al. 2014; Burgin et al. 2018); 70\% of marine fish, sea anemones, and scale insects (Eschmeyer et al. 2010, Fautin et al. 2013, Deng et al. 2016); > 60\% of micro- and macro-algae, amphibians, freshwater catfish (Guiry 2012; DeClerck et al. 2013; Ota et al. 2015; Giam et al. 2012). Rates of new species descriptions are also declining for terrestrial and marine ectoparasites, although not for marine endoparasitic helminths (Costello 2016).

From a sample of 370,000 terrestrial animals it was estimated using a statistical model that $70-80 \%$ of species have been named (Costello et al. 2012). Analysis of the numbers of undescribed marine species in 100 field studies suggested $64-69 \%$ had been named, whereas a statistical model based on rates of description overall species put the range at 28-70\% (median 43\%) (Appeltans et al. 20121). Globally, of the number of species predicted to be described by $2100,62 \%$ of amphipods (Arfianti et al. 2018), 69\% of polychaetes (Pamungkas et al. 2019), and 80\% of living and $90 \%$ of fossil Bryozoans (Pagès-Escolà et al. 2020) have been already described.

The most extreme hyper-estimates of how many species exist are either based on genetic rather than phenotypic diversity or avoid any mention of what they consider a species. Other flawed methods of estimating global species richness extrapolate from local samples to global, without accounting for the facts that species richness and the proportions of species in different taxa vary geographically, and the great differences in geographic range sizes between taxa (reviewed in Wilson and Costello 2005; Costello 2015; Costello and Chaudhary 2017). Using the rate of description of higher taxa to predict lower taxa discoveries generates highly variable estimates (overlapping zero in some cases), even when recent changes to Kingdom classifications are omitted, and is a fundamentally compromised method because higher taxa are an administrative construct (DeClerck et al. 2013). If there were a relationship between the number of higher taxa (e.g., phyla, classes) and species, then there would be more marine than terrestrial species because there are 13 phyla unique to the oceans; but just $15 \%$ of all species are marine (Costello \& Chaudhary 2017). Yet, too many papers uncritically repeat the hyper-estimates, or say "up to" a number without providing a best or lower bound to the estimate. This creates an "anchoring bias" in readers minds about global species richness (Costello 2015), leading some to ignore or dismiss more pragmatic and reasoned estimates (Costello 2019).

The naming of over one million species is impressive progress, although unfortunately a lot of largely wasted effort has gone into naming species multiple times, especially popular taxa. Some $40-90 \%$ of names for a range of taxa have already been recognised as synonyms, so it is possible that at least another $20 \%$ of currently accepted names may yet be found to be synonyms (Costello et al. 2013b). When the yet unresolved synonyms are reconciled, and the increased effort in the past 60 years is accounted for, I consider there will be closer to two million valid phenotypically distinct species named, and most will have been named by the end of the present century. 


\section{References}

Alroy, J. (2002) How many named species are valid? Proceedings of the National Academy of Sciences, 99 (6), 3706-3711. https://doi.org/10.1073/pnas.062691099

Anderson, J.G. (2017) Why ecology needs natural history. American Scientist, 105 (5), 290-298. https://doi.org/10.1511/2017.105.5.290

Arfianti, T, Wilson, S. \& Costello, M.J. (2018) Progress in the discovery of amphipod crustaceans. PeerJ, 6, e5187 https://doi.org/10.7717/peerj.5187

Bebber, D.P., Wood, J.R., Barker, C. \& Scotland, R.W. (2014) Author inflation masks global capacity for species discovery in flowering plants. New Phytologist, 201, 700-706. https://doi.org/10.1111/nph.12522

Bebber, D.P., Carine, M.A., Wood, J.R.I., Wortley, A.H., Harris, D.J., Prance, G.T., Davidse, G., Paige, J., Pennington, T.D., Robson, N.K.B. \& Scotland, RW. (2010) Herbaria are a major frontier for species discovery. Proceedings of the National Academy of Sciences USA, 107, 22169-22171. https://doi.org/10.1073/pnas.1011841108

Bebber, D.P., Marriott, F.H., Gaston, K.J., Harris, S.A. \& Scotland, R.W. (2007) Predicting unknown species numbers using discovery curves. Proceedings of the Royal Society B: Biological Sciences, 274 (1618), 1651-1658. https://doi.org/10.1098/rspb.2007.0464

BHL Consortium. (2020). Biodiversity Heritage Library. Available from: https://www.biodiversitylibrary.org (Accessed 1 Mar. 2020)

Bisby, F.A. (2000) The quiet revolution: biodiversity informatics and the internet. Science, 289 (5488), 2309-2312. https://doi.org/10.1126/science.289.5488.2309

Boero, F. (2010) The study of species in the era of biodiversity: a tale of stupidity. Diversity, 2 (1), 115-126. https://doi.org/10.3390/d2010115

Borkent, A. (2020) Shrinking biodiversity, dwindling taxonomy and building a broader science. Megataxa, 1, 49-52. https://doi.org/10.11646/megataxa.1.1.11

Boxshall, G. \& Self, D. (2011) UK Taxonomy \& Systematics Review-2010. Results of survey undertaken by the Review Team at the Natural History Museum serving as contractors to the Natural Environment Research Council (NERC).

Britz R., Hundsdörfer A. \& Fritz U. (2020) Funding, training, permits-the three big challenges of taxonomy. Megataxa, 1 , 46-48.

https://doi.org/10.11646/megataxa.1.1.10

Burgin, C.J., Colella, J.P., Kahn, P.L. \& Upham, N.S. (2018) How many species of mammals are there? Journal of Mammalogy, 99 (1), 1-14. https://doi.org/10.1093/jmammal/gyx147

Christenhusz M.J.M. (2020) On species concepts, phylogenetics and the science of natural history-three current issues facing taxonomy. Megataxa, 1, 63-66.

https://doi.org/10.11646/megataxa.1.1.14

Costello M.J. (2015) Biodiversity: the known, unknown and rates of extinction. Current Biology, 25 (9), R368-R371 https://doi.org/10.1016/j.cub.2015.03.051

Costello, M.J., Emblow C.S. \& Picton B.E. (1996) Long term trends in the discovery of marine species new to science which occur in Britain and Ireland. Journal of the marine biological Association of the United Kingdom, 76, 255-257. https://doi.org/10.1017/S0025315400029234

Costello, M.J., Vanhoorne B. \& Appeltans, W. (2015a) Progressing conservation of biodiversity through taxonomy, data publication and collaborative infrastructures. Conservation Biology, 29 (4), 1094-1099.

https://doi.org/10.1111/cobi.12496

Costello, M.J., Appeltans, W., Bailly, N., Berendsohn, W.G., de Jong, Y., Edwards, M., Froese, R., Huettmann, F., Los, W., Mees, J., Segers, H. \& Bisby, FA. (2014c) Strategies for the sustainability of online open-access biodiversity databases. Biological Conservation, 173, 155-165.

https://doi.org/10.1016/j.biocon.2013.07.042

Costello, M.J., Bouchet, P., Boxshall, G., Fauchald, K., Gordon, D.P., Hoeksema, B.W., Poore, G.C.B, van Soest, R.W.M., Stöhr, S., Walter, T.C., Vanhoorne, B, Decock, W. \& Appeltans, W. (2013a) Global coordination and standardisation in marine biodiversity through the World Register of Marine Species (WoRMS) and related databases. PLoS ONE, 8 (1), e51629. https://doi.org/10.1371/journal.pone.0051629

Costello, M.J. \& Chaudhary, C. (2017) Marine biodiversity, biogeography, deep-sea gradients, and conservation. Current Biology, 27, R511-R527. https://doi.org/10.1016/j.cub.2017.04.060

Costello, M.J., Horton, T. \& Kroh, A. (2018) Sustainable biodiversity databasing: international, collaborative, dynamic, centralised. Trends in Ecology and Evolution, 33 (11), 803-805. https://doi.org/10.1016/j.tree.2018.08.006

Costello, M.J., Houlding, B. \& Wilson, S. (2014b) As in other taxa, relatively fewer beetles are being described by an increasing number of authors: Response to Löbl and Leschen. Systematic Entomology, 39, 395-399.

https://doi.org/10.1111/syen.12068

Costello, M.J, Lane, M., Wilson, S. \& Houlding, B. (2015b) Factors influencing when species are first named and estimating global species richness. Global Ecology and Conservation, 4, 243-254.

https://doi.org/10.1016/j.gecco.2015.07.001

Costello, M.J., May, R.M. \& Stork, N.E. (2013b) Can we name Earth's species before they go extinct? Science, 339, 413416.

https://doi.org/10.1126/science. 1230318

Costello, M.J., May, R.M. \& Stork N.E. (2013c) Response to Comments on "Can we name Earth's species before they go extinct?" Science, 341, 237.

https://doi.org/10.1126/science.1237381

Costello, M.J. \& Wieczorek, J. (2014) Best practice for biodiversity data management and publication. Biological Conservation, $173,68-73$.

https://doi.org/10.1016/j.biocon.2013.10.018

Costello, M.J., Wilson, S.P. \& Houlding, B. (2012). Predicting total global species richness using rates of species description and estimates of taxonomic effort. Systematic Biology, 61(5), 871-883. https://doi.org/10.1093/sysbio/syr080

Costello, M.J. \& Wilson, S.P. (2011) Predicting the number of known and unknown species in European seas using rates of description. Global Ecology and Biogeography, 20, 319330 . https://doi.org/10.1111/j.1466-8238.2010.00603.x

Costello, M.J., Houlding, B. \& Joppa, L. (2014a) Further evidence of more taxonomists discovering new species, and that most species have been named: response to Bebber et al. (2014). New Phytologist, 202, 739-740. https://doi.org/10.1111/nph.12689

Costello, M.J. Wilson, S. \& Houlding, B. (2013d) More taxonomists but a declining catch of species discovered per unit effort. 
Systematic Biology, 62 (4), 616-624.

https://doi.org/10.1093/sysbio/syt024

Costello, M.J. (2016) Global biodiversity and biogeography of parasites. Integrative and Comparative Biology, 56, E44E44.

Costello, M.J. (2019) Unhelpful inflation of threatened species. Science, 365 (6451), 332-333. https://doi.org/10.1126/science.aay3467

Costello, M.J., Emblow, C.S., Bouchet, P. \& Legakis, A. (2006) European marine biodiversity inventory and taxonomic resources: state of the art and gaps in knowledge. Marine Ecology Progress Series, 316, 257-268. https://doi.org/10.3354/meps316257

David, J., Garrity, G.M., Greuter, W., Hawksworth, D.L., Jahn, R., Kirk, P.M., McNeill, J., Michel, E., Knapp, S., Patterson, D.J. \& Tindall, B.J. (2012) Biological nomenclature terms for facilitating communication in the naming of organisms. ZooKeys, 192, 67. https://doi.org/10.3897/zookeys.192.3347

Dayton, P.K. \& Sala, E. (2001) Natural history: the sense of wonder, creativity and progress in ecology. Scientia Marina, 65(S2), 199-206. https://doi.org/10.3989/scimar.2001.65s2199

De Clerck O., Guiry M.D., Leliaert F., Samyn Y. \& Verbruggen H. (2013) Algal taxonomy: a road to nowhere? Journal of Phycology, 49(2):215-225. https://doi.org/10.1111/jpy.12020

Deng, J., Li, K., Chen, C., Wu, S. \& Huang, X. (2016) Discovery pattern and species number of scale insects (Hemiptera: Coccoidea). PeerJ, 4, p.e2526. https://doi.org/10.7717/peerj.2526

Deng, J., Wang, X., Zeng, L., Zou, X. \& Huang, X. (2019) Dynamics of global institutional collaboration in insect taxonomy reveal imbalance of taxonomic effort. Insect Conservation and Diversity, 12 (1), 18-28.

https://doi.org/10.1111/icad.12298

Edgar, G.J. \& Stuart-Smith, R.D. (2014) Systematic global assessment of reef fish communities by the Reef Life Survey program. Scientific Data, 1(1), 1-8. https://oi.org/10.1038/sdata.2014.7

Eschmeyer, W.N., Fricke R., Fong, J.D. \& Polack, D. (2010) Marine fish biodiversity: A history of knowledge and discovery (Pisces). Zootaxa, 2525, 19-50. https://doi.org/10.11646/zootaxa.2525.1.2

Fautin, D.G., Malarky, L. \& Soberón, J. (2013) Latitudinal diversity of sea anemones (Cnidaria: Actiniaria). The Biological Bulletin, 224 (2), 89-98. https://doi.org/10.1086/BBLv224n2p89

Fontaine, B., van Achterberg, K., Alonso-Zarazaga, M.A., Araujo, R., Asche, M., Aspöck, H., Aspöck, U., Audisio, P., Aukema, B., Bailly, N., Balsamo, M., Bank, R.A., Belfiore, C., Bogdanowicz, W., Boxshall, G., Burckhardt, D., Chylarecki, P., Deharveng, L., Dubois, A., Enghoff, H., Fochetti, R., Fontaine, C., Gargominy, O., Gomez Lopez, M.S., Goujet, D., Harvey, M.S., Heller, K.G., van Helsdingen, P., Hoch, H., De Jong, Y., Karsholt, O., Los, W., Magowski, W., Massard, J.A., McInnes, S.J., Mendes, L.F., Mey, E., Michelsen, V., Minelli, A., Nafrýa, J.M.N., van Nieukerken, E.J., Pape, T., De Prins, W., Ramos, M., Ricci, C., Roselaar, C., Rota, E., Segers, H., Timm, T., van Tol, J. \& Bouchet, P. (2012) New Species in the Old World: Europe as a frontier in biodiversity exploration, a test bed for 21 st century taxonomy. PLOS ONE, 7 (5), e36881. https://doi.org/10.1371/journal.pone.0036881

Giam, X., Scheffers, B.R., Sodhi, N.S., Wilcove, D.S., Ceballos, G. \& Ehrlich, P.R. (2012) Reservoirs of richness: least disturbed tropical forests are centres of undescribed species diversity. Proceedings of the Royal Society B: Biological Sciences, 279 (1726), 67-76. https://doi.org/10.1098/rspb.2011.0433

Gordon, D.P., Beaumont, J., MacDiarmid, A., Robertson, D.A. \& Ahyong, S.T. (2010) Marine Biodiversity of Aotearoa New Zealand. PLoS ONE, 5 (8), e10905. https://doi.org/10.1371/journal.pone.0010905

Gordon, D.P. \& Costello, M.J. (2016) Bryozoa - not a minor phylum. New Zealand Science Review, 73 (3), 63-66.

Griffiths, C.L. (2005) Coastal marine biodiversity in East Africa. Indian Journal of Marine Sciences, 34 (1), 35-41.

Guiry, M.D. (2012) How many species of algae are there?. Journal of Phycology, 48(5), 1057-1063. https://doi.org/10.1111/j.1529-8817.2012.01222.x

Guiry, M.D. \& Guiry, G.M. (2020) AlgaeBase. World-wide electronic publication, National University of Ireland, Galway. Available from: https://www.algaebase.org (Accessed $24 \mathrm{Feb}$. 2020)

Hobern, D., Baptiste, B., Copas, K., Guralnick, R., Hahn, A., van Huis, E., Kim, E.S., McGeoch, M., Naicker, I., Navarro, L. \& Noesgaard, D. (2019) Connecting data and expertise: a new alliance for biodiversity knowledge. Biodiversity Data Journal, 7, e33679.

https://doi.org/10.3897/BDJ.7.e33679

Hutchings, P.A. (2020) Major issues facing taxonomy-a personal perspective. Megataxa, 1, 43-45. https://doi.org/10.11646/megataxa.1.1.9

Joppa, L.N., Roberts, D.L. \& Pimm, S.L. (2011) The population ecology and social behaviour of taxonomists. Trends in Ecology and Evolution, 26, 551-553. https://doi.org/10.1016/j.tree.2011.07.010

Kroh, A., Costello, M.J. \& Horton, T. (2019) Biodiversity databases in the future: reply to Cene Fišer. Trends in Ecology and Evolution, 34 (3), 185-186. https://doi.org/10.1016/j.tree.2018.12.011

Liu, Y., Dietrich, C., Braxton, S. \& Wang, Y. (2019) Publishing trends and productivity in insect taxonomy from 1946 through 2012 based on an analysis of the Zoological Record for four species-rich families. European Journal of Taxonomy, 504, $1-24$. https://doi.org/10.5852/ejt.2019.504

Lohrmann, V., Vohland, K., Ohl, M. \& Häuser, C. (2012) Taxonomische Forschungin Deutschland - Eine Übersichtsstudie. Museum für Naturkunde, Berlin. Available from: http://www.biodiversity.de/images/stories/Downloads/ taxo-studie-2012.pdf (Accessed 17 Jun. 2012)

Lovejoy, T.E., Brouillet, L., Doolittle, W.F., Gonzalez, A., Green, D.M., Hall, P., Hebert, P., Herrmann, T.M., Hyde, D., Lee, J. \& Maddison, W.P. (2010) Canadian taxonomy: exploring biodiversity, creating opportunity. The Expert Panel on Biodiversity Science. Council of Canadian Academies, Ottawa.

Ota, R.R., Message, H.J., da Graça, W.J. \& Pavanelli, C.S. (2015) Neotropical Siluriformes as a model for insights on determining biodiversity of animal groups. PLOS ONE, 10 (7), e0132913.

https://doi.org/10.1371/journal.pone.0132913

Pagès-Escolà, M., Bock, P.E., Gordon, D.P., Wilson, S., Linares, C., Hereu, B. \& Costello, M.J. (2020) Progress in the discovery 
of extant and fossil bryozoans. Marine Ecology Progress Series, 635, 71-79.

https://doi.org/10.3354/meps13201

Pamungkas, J., Glasby, C.J., Read, G.B., Wilson, S.P. \& Costello, M.J. (2019) Progress and perspectives in the discovery of polychaete worms (Annelida) of the world. Helgoland Marine Research, 73, 4.

https://doi.org/10.1186/s10152-019-0524-Z

Pimm, S.L., Jenkins, C.N., Joppa, L.N., Roberts, D.L. \& Russell, G.J. (2010) How many endangered species remain to be discovered in Brazil. Natureza \& Conservação, 8 (1), 71-77. https://doi.org/10.4322/natcon.00801011

Robbins, R.K. \& Opler, P.A. (1997) Butterfly diversity and a preliminary comparison with bird and mammal diversity. In: Erwin, T.L., Reaka-Kudla, M.L., Wilson, D.E. \& Wilson, E.O. (eds). Biodiversity II. Understanding and Protecting Our Biological Resources. Joseph Henry Press, pp. 69-82.

Roskov, Y., Ower, G., Orrell, T., Nicolson, D., Bailly, N., Kirk ,P.M., Bourgoin, T., DeWalt, R.E., Decock, W., Nieukerken, E. van, Zarucchi, J., Penev, L. (eds.) (2019) Species 2000 \& ITIS Catalogue of Life, 2019 Annual Checklist. Digital resource at www.catalogueoflife.org/annual-checklist/2019. Species 2000: Naturalis, Leiden, the Netherlands. ISSN 2405-884X.

Sullivan, B.L., Aycrigg, J.L., Barry, J.H., Bonney, R.E., Bruns, N., Cooper, C.B., Damoulas, T., D'Hondt, A.A., Dietterich, T., Farnsworth, A. \& Fink, D. (2014) The eBird enterprise: an integrated approach to development and application of citizen science. Biological Conservation, 169, 31-40. https://doi.org/10.1016/j.biocon.2013.11.003
Taxonomy Decadal Plan Working Group (2018) Discovering Diversity: A decadal plan for taxonomy and biosystematics in Australia and New Zealand 2018-2028. Australian Academy of Science and Royal Society Te Apârangi: Canberra and Wellington., $82 \mathrm{pp}$.

Tedesco, P.A., Bigorne, R., Bogan, A.E., Giam, X., Jézéquel, C. \& Hugueny, B. (2014) Estimating how many undescribed species have gone extinct. Conservation Biology, 28 (5),1360-1370. https://doi.org/10.1111/cobi.12285

Unger, S., Rollins, M., Tietz, A. \& Dumais, H. (2020) iNaturalist as an engaging tool for identifying organisms in outdoor activities. Journal of Biological Education, 1-11. https://doi.org/10.1080/00219266.2020.1739114

Wei, W., Luo, G., Ran, J. \& Li, J. (2020) Zilong: A tool to identify empty images in camera-trap data. Ecological Informatics, 55,101021 . https://doi.org/10.1016/j.ecoinf.2019.101021

Wilson, S.P. \& Costello, M.J. (2005) Predicting future discoveries of European marine species by using a non-homogeneous renewal process. Applied Statistics, 54 (5), 897-918. https://doi.org/10.1111/j.1467-9876.2005.00513.x

Woodley, M.A., Naish, D. \& Shanahan, H.P. (2008) How many extant pinniped species remain to be described? Historical Biology, 20 (4), 225-235.

https://doi.org/10.1080/08912960902830210

Zhang, Z.-Q. (2020) Megataxa for big science questions in taxonomy. Megataxa, 1 (1), 1-3.

http://dx.doi.org/10.11646/megataxa.1.1.1 